\title{
Intellectual ability in Tuberous Sclerosis Complex correlates with predicted effects of mutations on TSC1 and TSC2
}

\section{proteins}

Ho Tin Wong, ${ }^{1}$ Deborah L McCartney, ${ }^{2}$ Julia C Lewis, ${ }^{2}$ Julian R Sampson, ${ }^{2}$

Christopher J Howe, ${ }^{3}$ Petrus J de Vries ${ }^{4}$

${ }^{1}$ St James's University Hospital, Beckett Street, Leeds, West Yorkshire, LS9 7TF, UK, ${ }^{2}$ Institute of Medical Genetics, School of Medicine, Cardiff University, Cardiff, CF14 4XN, UK, ${ }^{3}$ Department of Biochemistry, University of Cambridge, Tennis Court Road, Cambridge, CB2 1QW, UK, ${ }^{4}$ Division of Child \& Adolescent Psychiatry, University of Cape Town, 46 Sawkins Road, Rondebosch, 7700, South Africa

Correspondence to: P J de Vries (petrus.devries@uct.ac.za) 


\begin{abstract}

\section{Background}

Tuberous sclerosis complex is a multisystem genetic disease, caused by mutation in the TSC1 or TSC2 genes, associated with many features, including intellectual disability (ID). We examined psychometric profiles of patients with TSC1 or TSC2 mutations and tested if different mutation types were associated with different degrees of intellectual ability.
\end{abstract}

\title{
Methods
}

One hundred subjects with known TSC1/TSC2 mutations were assessed using a range of IQ (intellectual quotient) or DQ (developmental quotient) measures. Effects of mutations on TSC1/TSC2 proteins were inferred from sequence data and published biochemical studies.

\section{Results}

Most individuals with TSC1 mutations fell on a normal distribution identical to the general population, with $\sim 10 \%$ showing profound ID. Of individuals with $T S C 2$ mutations, 34\% showed profound ID, and the remainder a pattern of IQ/DQ more variable and shifted to the left than in TSCl or the general population. Truncating TSC1 mutations were all predicted to be subject to nonsense-mediated mRNA decay. Mutations predicted to result in unstable protein were associated with less severe effects on IQ/DQ. There was a statistically significant negative correlation between length of predicted aberrant C-terminal tails arising from frameshift mutations in TSC1 and IQ/DQ; for TSC2 a positive but not statistically significant correlation was observed. 


\section{Conclusion}

We propose a model where (i) IQ/DQ correlates inversely with predicted levels and/or deleterious biochemical effects of mutant TSC1 or TSC2 protein, and (ii) longer aberrant $\mathrm{C}$-terminal tails arising from frameshift mutations are more detrimental for TSC1 and less for TSC2. Predictions of the model require replication and biochemical testing.

\section{Key words}

genotype-phenotype / tuberous sclerosis complex / tuberin / hamartin / nonsensemediated decay 


\section{INTRODUCTION}

Tuberous sclerosis complex (TSC) is a multisystem genetic disease with widespread manifestations including neuropsychiatric features such as intellectual disability (ID)[1,2]. It is an autosomal dominant disorder caused by mutations in the TSC1 [3] or TSC2 [4] genes. Roles attributed to TSC1 include stabilisation and correct localisation of TSC2 [5,6]. The TSC1-TSC2-TBC1D7 complex [7-9] modulates multiple intracellular processes, notably through TSC2's GTPase activating protein (GAP) domain [10]. The GAP activity of TSC2 counteracts stimulation by RAShomologue enriched in brain (Rheb) of mammalian (or mechanistic) target of rapamycin complex 1 (mTORC1), which phosphorylates proteins including p70 S6 kinase (S6K1) [9,11]. TSC1 and TSC2 receive many inputs with activating or inhibitory effects on signalling [1], and loss of TSC1/TSC2 disturbs downstream signalling.

Intellectual disability (ID) is defined as an Intelligence Quotient (IQ) below 2 standard deviations of the mean $(\mathrm{IQ} / \mathrm{DQ}<70)$, and associated functional impairment in daily life [12]. Although prevalence of ID in the general population is approximately $2.2 \%$, epidemiological analysis of TSC in south-west England showed ID prevalence in TSC of 44.4\% [13]. The pattern of ID was not a typical unimodal Gaussian distribution, but bimodal, with $70 \%$ of individuals on a normal distribution shifted slightly down $($ mean $(\mu)=93.6$, standard deviation $(\sigma)=13.8)$ and $30 \%$ with 'profound' intellectual disability $(\mu<20)[13,14]$. 
Until discovery of the roles of the TSC1-TSC2-TBC1D7 complex, it was assumed that the predominant causal contributions to intellectual and neurocognitive manifestations of TSC were from structural abnormalities (cortical tubers), seizure phenomena (epilepsy) or interaction between the two $[15,16]$. However, de Vries and Howe suggested that seizures and tubers were neither necessary nor sufficient to explain the neuropsychiatric variability of TSC [17]. For example, less than $50 \%$ of IQ variance was explained by seizure and tuber factors in the study by O'Callaghan et al [16]. Instead de Vries and Howe proposed TSC-associated neuropsychiatric disorders to be direct molecular consequences of disturbance of cell signalling/development [17 and refs therein]. Supporting this, animal models show a direct route from mutation to disruption of neurocognitive functions through mTOR overactivation [17-19]. There is also evidence for reversal of neurocognitive manifestations by mTOR inhibitors in animal models $[19,20]$ and possibly in humans [21].

Consequences of mutations in TSC2 are typically more severe than for TSC1 [22-27]. De Vries and Howe proposed that, given that not all mutations were necessarily null, different mutations within TSC1 or TSC2 would have different consequences according to biochemical effects on the proteins [17]. This raised the possibility of using the nature of a given mutation to predict intellectual ability in TSC individuals, which could be scientifically and clinically valuable.

To date only three studies of genotype-phenotype associations in TSC utilised validated and standardised measures of intellectual ability/developmental level [24,27,28]. Lewis et al. [24] measured IQ of 92 individuals with TSC and known 
mutations, performing a categorical genotype-phenotype analysis, dividing subjects into 'impaired' and 'non-impaired' based on IQ score below or above 70. They suggested TSC2 mutations were more likely to be associated with ID than TSC1 mutations. Jansen and colleagues performed comprehensive neuropsychological assessment of 59 TSC subjects [27]. The battery included measures of IQ, memory, attentional and executive skills and motor reaction times, and a 'cognition index' was calculated by summing scaled scores across neuropsychological domains. They concluded that $T S C 1$ and TSC2 'groups overlapped almost completely' and prediction of cognitive phenotype should not be based on whether an individual had a TSC1 or TSC2 mutation.

In the most recent genotype-phenotype study of IQ in TSC, van Eeghen et al. examined 137 subjects from a clinical case series [28], utilizing a range of standardised IQ/DQ measures. Rates of ID were $23 \%$ in those with $T S C 1$ and $59 \%$ in those with TSC2 mutations, and several inter-mutational correlations were observed, some contrasting with earlier findings.

These studies had methodological weaknesses, particularly in the psychometric approach to IQ/DQ data. Intelligence is not a categorical phenomenon, being normally distributed across a population with $\mu=100$ and $\sigma=15$. Given that IQ/DQ distribution in TSC is bimodal, de Vries and Prather suggested that individuals in the profoundly impaired range $(\mathrm{IQ}<20)$ and those in the normal distribution be considered as separate cognitive phenotypes, perhaps representing different underlying mechanisms [14]. Statistically, it is inappropriate to perform parametric analysis with the TSC distribution pattern. Earlier studies [24,28] did not examine the actual shape 
of IQ distribution across TSC1 and TSC2, represented by mean and standard deviation data. TSC2 may, for instance, have been reported as more severe than TSC1 because most individuals with profound ID had a TSC2 mutation. There are two main criticisms of the study by Jansen et al. [27]. In spite of the comprehensive neuropsychological battery, scores were collapsed into 4 categories. Given that a score of 1 represented performance $<70$, more than $50 \%$ of the study data would have been in this category, preventing separation of mild, moderate, severe and profound intellectual disability. Secondly, Jansen's 'cognition index' is of unknown biological meaning, since neurobiological substrates of skills such as memory, attention, executive skills and motor function are highly different, and mutational or molecular correlates may be domain specific.

In van Eeghen et al's study only $44 \%$ of the clinic series had neuropsychological evaluations, possibly skewing the sample towards milder phenotypes as shown by the low proportion with profound ID [28]. No mean and standard deviation data were presented, limiting interpretation of the 'shape' of IQ/DQ distributions. Also the study did not consider familial/sporadic status (the latter being associated with a more severe phenotype [22]) resulting in a possible ascertainment bias.

Given the earlier proposal that different mutation types have different effects [17], we tested if different kinds of TSC1 or TSC2 mutations correlated with effects on IQ/DQ. We were interested in predicted effects of mutations on levels of mutant proteins through nonsense-mediated decay (NMD) or protein degradation (PD). NMD is a degradation-mediated reduction in levels of transcripts carrying premature termination codons (PTC), occurring if the PTC is shortly before the last exon-exon junction [29]. 
NMD has been demonstrated for TSC1 but was shown to be incomplete in RNA isolated from blood, and from lymphoid and fibroblast cell lines [30], raising the possibility that mutant protein might be present in individuals with TSC1 or TSC2 mutations. We therefore tested for association between the predicted nature of any residual mutant protein and phenotype. PD is known to cause significant reduction in levels of TSC1 with mutations close to the $\mathrm{N}$ terminus [31-33].

We examined the association between genotype and intellectual phenotype, extending and reanalysing the sample used by Lewis et al. [24], and interpret the results in terms of a model for stability and effects of mutant proteins.

\section{METHODS}

\section{Subjects}

Ninety-two unrelated subjects were recruited and assessed as described previously (the 'Cardiff' study) [24]. An additional 21 unrelated subjects were volunteers from the Tuberous Sclerosis Association, UK, recruited for a separate ('Cambridge') study [34]. After confirmation of clinical criteria for TSC [35], subjects consented for their information to be used for research. Protocols received ethical approval. Only subjects with complete psychological and genetic profiles were included, excluding individuals with no mutation identified, no IQ/DQ score, or undetermined TSC1/TSC2 status. 


\section{IQ/DQ assessments}

In the Cardiff study, JCL assessed IQ using Wechsler Adult Intelligence Scale Revised (WAIS-R) [36], Wechsler Intelligence Scale for Children III (WISC-III) [37], Raven's Coloured Progressive Matrices (RCPM) [38] or the Vineland Adaptive Behaviour Scale (VABS) [39]. WAIS-R and WISC-III are standard measures of IQ suitable for individuals able to participate in direct testing. The floor of IQ measurement using these tools is $\sim 45$. Although WAIS-R and WISC-III are more reliable, they are unsuitable to determine IQs in individuals with lower abilities. In these cases the RCPM or VABS may be useful. RCPM is recognised as a measure of 'fluid intelligence' whereas VABS is an indirect measure of adaptive behaviours in daily life, used to estimate a developmental quotient (DQ) as proxy for IQ. In the Cambridge study, DLM used the Wechsler Abbreviated Scale of Intelligence (WASI), WISC-III or WAIS-R [40] to calculate full-scale IQ. Given the challenges of measurement across age and ability, we calculated a 'best estimate IQ/DQ' using a hierarchical approach (WAIS-R/WISC-III $>$ WASI $>$ RCPM $>$ VABS). As per ICD10 convention, ID was defined as IQ/DQ $<70$ and profound ID as IQ/DQ $<20$ [41].

\section{Mutation detection and categorisation}

Mutations were analysed by screening coding sequences and intronic splice site regions of $T S C 1$ and $T S C 2$, using single strand conformation polymorphism analysis, denaturing high performance liquid chromatography, high resolution melt analysis and Sanger sequencing, and assessing both loci for large rearrangements using multiplex probe ligation analysis $[42,43]$. Mutations were categorised as missense, 
nonsense, frameshift, in-frame deletions, large deletions, splice-site mutations and undetermined. Missense mutations were classified as non-conservative if they resulted in substitution between biochemical groups as defined by Clustal X [44]. Regions of TSC1 and TSC2 considered in mutation mapping are shown in Supplementary Figure 1. NMD was predicted if the PTC either generated directly by mutation, or resulting from a frameshift, was $>18$ codons upstream of the last exon-exon junction [29]. Junctions were as in the Leiden Open Variation Database (LOVD) TSC1 and TSC2 reference sequences [45]. Splice-site mutations, splice variants and possible effects on splicing of mutations away from splice sites were not considered, given the lack of detailed information on splicing. For frameshifts, the position of the next termination codon and the length of the 'aberrant tail' between it and the mutation site were determined using the LOVD sequences. To predict mutation distributions we assumed that each codon in TSC1 and TSC2 was equally likely to mutate to a PTC. Thus 190/1164 (16.3\%) of possible TSC1 truncation or frameshift mutations were predicted not to result in NMD, as the final exon-exon boundary occurs 172 codons prior to the 3 ' end of the coding sequence, and 974/1164 (83.7\%) were predicted to result in NMD. Similarly, 72/1807 (4.0\%) of possible TSC2 mutations were predicted not to result in NMD and 1735/1807 (96.0\%) were predicted to result in NMD. For TSC1 we carried out additional calculations using the reference sequence to estimate the actual number of positions at which a single insertion, deletion or substitution could lead to escape from NMD. We assumed insertions and deletions were equally likely, and calculated under models in which (i) only transitions occurred or (ii) transitions and transversions were equally likely. For TSC1 truncating mutations, PD was predicted to occur if the PTC was within the first 350 codons [32], although it is recognized that some non-pathogenic mutations in this region may not affect the 
structure [46] and some mutations outside this region may destabilise the protein. Thus $350 / 1164(30.1 \%)$ of possible truncating mutations were predicted to exhibit PD. Predicted and observed numbers of mutations showing PD and/or NMD were evaluated from the population sample and from the LOVD database [45]. For TSC2 truncating mutations, the GAP status was assumed to depend on whether the domain was fully intact (present) or truncated (absent).

\section{Statistical Analysis}

Data analysis was performed using SPSS version 21. Differences in IQ/DQ scores were analysed using the non-parametric Mann-Whitney U test. The KolmogorovSmirnov test was used to assess normality of IQ/DQ distributions above $19.2 \times 2$ contingency tables were assessed using Fisher's exact test. Spearman's rank correlation test was used to correlate two independent variables. A threshold of $\mathrm{p}<0.05$ was considered statistically significant in all tests and no corrections were made for multiple testing.

\section{RESULTS}

\section{Subject characteristics}

Of the 113 participants (92 from the Cardiff study [24] and 21 from the Cambridge study [34]), 13 were excluded because intellectual or genetic data were incomplete. Of the remaining 100 subjects, 26 had TSC1 and 74 TSC2 mutations. There were 47 males and 53 females, 82 sporadic and 15 familial cases, with 3 of undetermined familial/sporadic origin. Details of mutations are given in Supplementary Table 1. 


\section{IQ/DQ in TSC1 and TSC2}

IQ/DQ scores (Supplementary Figure 2) were stratified and compared to the expected distribution in the general population (Table 1). Proportions with profound impairment were 28\%, 11\% and 34\% (all, TSC1 and TSC2 respectively). Excluding subjects with profound ID, Kolmogorov-Smirnov tests showed normal distributions for remaining IQ scores (All $\mathrm{p}=0.574 ;$ TSC1 $\mathrm{p}=0.915 ;$ TSC2 $\mathrm{p}=0.551)$.

Table 1 Stratification of IQ/DQ in the normal population and of all, TSC1 and TSC2 subjects in the study $(n=100)$. The lower panel in grey shows subdivisions of the category with IQ $<70$.

\begin{tabular}{|c|c|c|c|c|c|}
\hline IQ & Description & $\begin{array}{l}\text { Normal } \\
\operatorname{pop}^{\mathrm{n}}(\%)\end{array}$ & $\begin{array}{l}\text { All subjects } \\
(\%)(n=100)\end{array}$ & $\begin{array}{c}\text { TSC1 subjects } \\
\text { (\%) }(\mathrm{n}=\mathbf{2 6})\end{array}$ & $\begin{array}{c}\text { TSC2 subjects } \\
(\%)(n=74)\end{array}$ \\
\hline$>130$ & Very superior & 2.2 & 0.0 & 0.0 & 0.0 \\
\hline $120-129$ & Superior & 6.7 & 3.0 & 11.5 & 0.0 \\
\hline $110-119$ & High average & 16.1 & 6.0 & 7.7 & 5.4 \\
\hline $90-109$ & Average & 50.0 & 20.0 & 42.3 & 12.2 \\
\hline $80-89$ & Low average & 16.1 & 12.0 & 15.4 & 10.8 \\
\hline $70-79$ & Borderline & 6.7 & 10.0 & 3.8 & 12.2 \\
\hline$<70$ & Extremely low & 2.2 & 49.0 & 19.2 & 59.5 \\
\hline $50-69$ & Mild ID & & $9 \%$ & $4 \%$ & $11 \%$ \\
\hline $35-49$ & Moderate ID & & $4 \%$ & $4 \%$ & $4 \%$ \\
\hline $20-34$ & Severe ID & & $8 \%$ & $0 \%$ & $11 \%$ \\
\hline$<20$ & Profound ID & & $28 \%$ & $11 \%$ & $34 \%$ \\
\hline
\end{tabular}

TSC2 was associated with significantly lower IQ/DQ than TSC1 (Table 2) and the association held after exclusion of cases with profound ID (IQ<20), and after removal of familial cases (reducing possible ascertainment bias). Of those with IQ/DQ $>20$ (i.e. the 'normal distribution phenotype' [14]), those with TSC1 mutations were psychometrically very similar to the general population $(\mu=97.5, \sigma=19.1$; compared to $\mu=100.0, \sigma=15.0)$. Those with $T S C 2$ mutations showed significantly lower mean IQ 
and very different psychometric distribution $(\mu=71.6, \sigma=27.1)$. No significant difference between males and females was seen across any comparison (Supplementary Table 2), with no significant gender differences in the proportion of those with ID (males $51.1 \%$ vs females $47.1 \%$ ) or profound ID (males $27.7 \%$ vs females $28.3 \%$ ).

Table 2 Means $(\mu)$ and standard deviations $(\sigma)$ of IQ/DQ with different TSC mutation status in the total sample, in those with IQ $>20$ and in the sporadic cases with IQ $>20$

\begin{tabular}{|c|c|c|c|c|c|}
\hline TSC status & Number & $\mu$ & $\sigma$ & $Z$ value & $\mathbf{P}$ \\
\hline \multicolumn{6}{|l|}{ Total sample } \\
\hline All individuals & 100 & 62.8 & 36.0 & & \\
\hline TSCl & 26 & 88.4 & 31.2 & & \\
\hline TSC2 & 74 & 53.8 & 33.3 & & \\
\hline$T S C 1$ vs $T S C 2$ & & & & -4.252 & $<0.001 *$ \\
\hline \multicolumn{6}{|l|}{ IQ $>20$ only } \\
\hline All individuals & 72 & 79.9 & 27.5 & & \\
\hline TSC1 & 23 & 97.5 & 19.1 & & \\
\hline$T S C 2$ & 49 & 71.6 & 27.1 & & \\
\hline$T S C 1$ vs $T S C 2$ & & & & -3.878 & $<0.001 *$ \\
\hline \multicolumn{6}{|c|}{ IQ>20 and sporadic only } \\
\hline All individuals & 54 & 78.8 & 26.9 & & \\
\hline$T S C 1$ & 11 & 94.8 & 22.9 & & \\
\hline TSC2 & 43 & 74.7 & 26.6 & & \\
\hline$T S C 1$ vs $T S C 2$ & & & & -2.353 & $0.019^{*}$ \\
\hline
\end{tabular}

\section{Mutation Characteristics for TSC1 - NMD, Protein Degradation and TSC2}

\section{interaction}

TSC1 frameshift mutations (Table 3 and Supplementary Fig 3A) were associated with significantly lower IQ/DQ than nonsense mutations (difference between mean IQ/DQ $=34.9 ; \mathrm{Z}=-2.233 ; \mathrm{p}=0.026)$. No TSC1 missense mutations were found. All 25 TSC1 truncating (i.e. nonsense or frameshift) mutations were predicted to result in NMD. 
Strikingly, all truncating mutations in TSC1 in the LOVD database [45] (2 May 2014) were also predicted to result in NMD, which was statistically highly significant compared to the null hypothesis that they were evenly distributed throughout the gene $(p<0.0001$, Table 4). Predictions based on the more detailed calculation of sites where a single mutation could result in escape from NMD gave similar conclusions (not shown).

Table 3 Means $(\mu)$ and standard deviations $(\sigma)$ of IQ/DQ with different mutational categories in TSC1 and TSC2

\begin{tabular}{lccccc}
\hline Mutation category & Number & $\boldsymbol{\mu}$ & $\boldsymbol{\sigma}$ & $\mathbf{Z}$ value & $\mathbf{P}$ \\
\hline $\boldsymbol{T S C \boldsymbol { 1 }}$ & 14 & 103.0 & 16.5 & & \\
Nonsense & 11 & 68.1 & 36.0 & & \\
Frameshift & & & & -2.233 & $0.026^{*}$ \\
Nonsense vs frameshift & & & & & \\
& 17 & 50.1 & 30.6 & & \\
NSC & 13 & 56.7 & 34.2 & & \\
Framense & & & & -0.558 & 0.577 \\
Nonsense vs frameshift & & &
\end{tabular}

Statistical comparisons were made with the Mann-Whitney U test. The individual with a TSC1 splice site mutation is omitted. * denotes a statistically significant result.

Table 4 Fisher's exact tests of the distribution of mutations predicted to be associated with nonsense-mediated decay (NMD) and protein degradation (PD) status in the sample and of all mutations listed in the TSC1 and TSC2 Leiden Open Variation Database (accessed on 2 May 2014). Individuals with splice site mutations are omitted.

\begin{tabular}{|c|c|c|c|}
\hline Type of analysis & Expected ratio & Observed Ratio & $\begin{array}{l}\text { Two-tailed } P \\
\text { value }\end{array}$ \\
\hline \multicolumn{4}{|c|}{ This study $($ TSC $1=25 ;$ TSC2 $=30)$} \\
\hline TSC1 (no NMD:NMD) & $4: 21$ & $0: 25$ & 0.111 \\
\hline TSC2 (no NMD: NMD) & $1: 29$ & $3: 27$ & 0.612 \\
\hline TSC1 (no PD:PD) & $17: 8$ & $15: 10$ & 0.551 \\
\hline \multicolumn{4}{|c|}{ LOVD Database $($ TSC $1=588 ;$ TSC $2=1020)$} \\
\hline TSC1 (no NMD:NMD) & $96: 492$ & $0: 588$ & $<0.0001^{*}$ \\
\hline$T S C 2$ (no NMD:NMD) & $41: 979$ & $45: 975$ & 0.741 \\
\hline TSC1 (no PD:PD) & 411:177 & $417: 171$ & 0.749 \\
\hline
\end{tabular}

* denotes a statistically significant result. 
The numbers of TSC1 mutations predicted to cause truncation in the region leading to protein degradation ('PD mutations') rather than the non-PD region ('no-PD mutations') in our dataset and the LOVD database were not significantly different from expectation. However, mutations predicted to result in PD were associated with higher IQ/DQ than non-PD mutations (Table 5). When only sporadic cases were considered, to reduce ascertainment bias, the difference was even more marked and significant (mean difference in $\mathrm{IQ} / \mathrm{DQ}=45.8 ; \mathrm{Z}=2.275 ; \mathrm{p}=0.027$ ). HoogeveenWesterveld et al. reported that substitutions in the first 224 amino acids could lead to protein instability [33]. Mutations in our dataset causing truncations within this more restricted region were also associated with a higher IQ/DQ than mutations leading to distal truncations, but sample numbers were too small for statistical analysis. Individuals with mutations within the tuberin-interaction domain (TID) of TSC1 showed higher mean IQ/DQ $(n=6, \mu=101.3, \sigma=13.6)$ than others $(n=19, \mu=83.3, \sigma=$ 34.6) and higher mean than those with mutations elsewhere in the first half of the protein $(n=7, \mu=90.4, \sigma=16.9)$. The differences were not significant, although this may reflect small sample sizes.

Table 5 Means $(\mu)$ and standard deviations $(\sigma)$ of IQ/DQ with different expression categories in TSC1 and TSC2. Individuals with splice site mutations are omitted. 


\begin{tabular}{lccccc}
\hline Expression category & Number & $\boldsymbol{\mu}$ & $\boldsymbol{\sigma}$ & $\mathbf{Z}$ value & P \\
\hline $\boldsymbol{T S C 1}$ & 15 & 79.7 & 37.6 & & \\
No PD & 10 & 99.5 & 14.6 & & \\
PD & & & & 1.083 & 0.279 \\
No PD vs PD & & & & & \\
$\boldsymbol{T S C 1}$ sporadic cases only & 10 & 65.5 & 36.8 & & \\
No PD & 4 & 111.3 & 14.2 & & \\
PD & & & & 2.275 & $0.027^{*}$ \\
No PD vs PD & & & & & \\
TSC 2 & 3 & 31.0 & 20.8 & & \\
No NMD & 27 & 55.4 & 32.2 & & \\
NMD & & & & & \\
No NMD vs NMD & & & & & \\
TSC2 sporadic cases only & 3 & 31.0 & 20.8 & & \\
No NMD & 26 & 55.0 & 32.7 & & \\
NMD & & & & 1.326 & 0.185 \\
No NMD vs NMD &
\end{tabular}

Statistical comparisons were made with the Mann-Whitney U test. * denotes a statistically significant result.

\section{Correlation of predicted length of aberrant tail in TSC1 and IQ/DQ}

We tested for a correlation between the predicted lengths of aberrant tails generated by the frameshift or nonsense mutations and IQ/DQ (Figure 1A and Supplementary Table 3). Mutant proteins (frameshift or nonsense, 15 individuals) not predicted to be subject to PD showed significant negative correlation between tail length and IQ/DQ $($ rho $=-0.706 ; p=0.003)$

\section{Mutation Characteristics for TSC2 - NMD, TSC1 interaction and GAP status}

Unlike TSC1, there were several missense TSC2 mutations (supplementary Fig 3B). Most were non-conservative, suggesting that many conservative substitutions would be non-pathogenic. The single individual in the sample with a conservative substitution (L1594M) showed an IQ/DQ of 19. Van Eeghen et al. found that individuals with missense mutations in exons 22-33 were less seriously affected than 
individuals with mutations elsewhere [28]. In our study there was only one participant with a missense mutation in exons $22-33$, with $I Q / D Q=19$. Of the 12 with missense mutations elsewhere, five also had IQ/DQ $<20$. Missense mutations were associated with lower IQ/DQ than truncating mutations, but the difference was not significant $(\mathrm{n}=13, \mu=37.8, \sigma=29.8$ and $\mathrm{n}=30, \mu=52.9, \sigma=31.8$ respectively, $\mathrm{p}=0.224)$. Among truncating mutations, there was no significant difference between frameshift and nonsense mutations (Table 3). In-frame deletions were associated with a higher IQ/DQ $(n=4, \mu=71.0, \sigma=16.8)$ than truncations, but the sample was too small for statistical testing. There were 9 splice site mutations $(\mu=68.6, \sigma=29.8)$, and 18 large deletions $(\mu=55.8, \sigma=39.5)$.

For TSC2 PTC mutations the numbers of NMD and no-NMD mutations were not significantly different from expected, either in our dataset or in the LOVD database (Table 4). No-NMD mutations were associated with a lower IQ/DQ than NMD mutations $(\mathrm{n}=3 ; \mu=31 ; \sigma 20.8 ; \mathrm{n}=27 ; \mu=55.4 ; \sigma=32.2)$, although results were not statistically significant (Table 5).

There was one individual with a missense mutation in the TSC1-interaction domain of TSC2, defined as extending to the end of exon 11 [47], with IQ/DQ =21. When the region considered was extended (HID, dotted line in Supplementary Figure 1) to the N-terminal half of TSC2, including exon 22 (and including missense mutations potentially affecting the interaction domain as defined by van Eeghen et al.) there was no significant difference compared to individuals with missense mutations elsewhere. Van Eeghen et al. [28] by contrast found lower IQ/DQ for individuals with mutations in the interaction domain. Three of the 30 TSC2 truncating mutations were predicted 
to result in retention of the GAP domain, whereas 27 were predicted to result in its loss. IQ/DQ was not significantly different between the two groups $(n=3 ; \mu=31.0, \sigma=$ 20.8, and $\mathrm{n}=27 ; \mu=55.4, \sigma=32.2, \mathrm{Z}=-1.383 ; \mathrm{p}=0.167)$.

\section{Correlation of length of aberrant tail in predicted mutant TSC2 proteins and IQ/DQ}

After discounting the no-NMD mutations which may result in lower IQ/DQ for other reasons (see below) there was a positive, but not statistically significant, correlation $($ rho $=0.308 ; p=0.119)$ between length of predicted aberrant tail and IQ/DQ (Figure 1B and Supplementary Table 3). However, the nonsense mutations within this group showed a wide spread of IQ/DQ values.

\section{DISCUSSION}

\section{IQ/DQ distribution}

The IQ/DQ of our patients (Supplementary Figure 2) was comparable to those in another epidemiological study in the UK from 2003 [13]. Both studies showed bimodal IQ distribution, with similar proportions of ID and profound impairment ( $49.0 \%$ vs $44.4 \%$ and $28.0 \%$ vs $30.5 \%$ respectively), and suggesting our sample was representative of the TSC population at the time patient phenotypes were assessed.

Even excluding individuals with profound ID, the TSC1 and TSC2 'normal distribution' phenotypes [14] remained psychometrically and statistically significantly different, with TSC1 individuals psychometrically very similar to the general population, and TSC2 individuals associated with significantly lower IQ (Table 2). 
Results confirmed that the higher proportion of ID in TSC2 was not simply

attributable to more individuals with profound ID.

The lack of significant difference between males and females in mean IQ

(Supplementary Table 2) or the proportion of ID (males 51.1\% vs females $47.1 \%$ ) or

profound ID (males $27.7 \%$ vs females $28.3 \%$ ) refutes earlier, non-standardised reports suggesting more ID in males with TSC [25,26], and replicates the observations made by van Eeghen et al. [28].

\section{Mutation characteristics for TSC1}

The lack of TSC1 missense mutations in our sample of 26 individuals is consistent with previous reports that such mutations are rare [48]. It was remarkable that all 25 TSC1 truncating mutations in our sample and all 588 TSC1 truncating mutations in the LOVD database were predicted to show NMD. There are two possible interpretations. Truncation of the TSC1 protein within the C-terminal 190 residues may have such a slight effect that mutations do not cause TSC, and are not seen in a sample of individuals chosen because they have the disorder. Alternatively, TSC1 proteins truncated within the C-terminal 190 residues may be lethal if present at wild-type levels, because of a dominant effect. We favour the latter explanation, for two reasons. The TSC LOVD includes 157 TSC1 variants classified as having 'no known pathogenicity' [45] (Sept 2014) and 25 of these are located in the no-NMD region, consistent with expectation if equally distributed. However, none is a truncating mutation, although $56 \%$ of mutations overall result in truncation. Thus, if truncating mutations in the no-NMD region were indeed non-pathogenic, we would expect to see examples of them in LOVD. In addition, most truncating mutations in the no-NMD 
region would be expected to affect the ERM domain (believed to have an important role in mediating cell adhesion [49]) and a region involved in interaction with TSC2 [32]. Although the suggestion that truncating mutants of TSC1 not subject to NMD are embryonic-lethal because of dominant effects contrasts with the general view that TSC1 mutations have a mild phenotype, it is consistent with the demonstration [31] that TSC1 protein with substitutions at positions 50 or 117 can have a dominant negative effect, and the suggestion by these authors that protein with mutations elsewhere might also have a dominant negative effect [31].

A deleterious effect of mutant TSC1 would also explain our observation that individuals with mutations predicted to result in PD showed higher IQ/DQ than those with mutations outside the PD region. Because NMD does not lead to complete loss of transcripts [30], production of some truncated protein would be expected. We propose that this is not immediately degraded, but that lower levels persist for protein truncated within the PD region, resulting in less marked effects on IQ/DQ. In fact, these individuals showed a mean and standard deviation in IQ/DQ scores essentially identical to the general population. Furthermore, although no patients in this study had deletions of the entire TSCl gene, we have observed 13 patients with such deletions in a larger diagnostic series and none was reported to have ID. Given the location of the TSC2-interaction domain towards the $\mathrm{N}$ terminus of TSC1, it is not surprising that individuals with mutations in the interaction domain also showed higher IQ/DQ than others (although this contrasts with the observation of van Eeghen et al).

\section{Length of aberrant tail on TSC1}


For individuals with frameshift TSC1 mutations outside the PD region, effects on IQ/DQ were greater the longer the aberrant C-terminal tail on the predicted mutant protein, and frameshift mutations were associated with lower IQ than nonsense mutations. This could be explained if the aberrant tail increases the deleterious biochemical effects of the protein (or reduces its rate of degradation), again consistent with the notion that mutant protein is detrimental.

\section{Mutation characteristics for TSC2}

Results for TSC2 were quite different from those for TSC1, with no significant clustering of mutations in the NMD region in our population or in the TSC2 LOVD (Table 4). Although truncating mutations predicted to give rise to NMD were associated with a higher IQ/DQ than no-NMD mutations, this was not statistically significant (Table 5). These observations suggest that mutant TSC2 proteins truncated near the C-terminus are only slightly deleterious in terms of IQ/DQ. The calmodulinbinding domain, the oestrogen receptor alpha binding site and a target site for the ribosomal protein S6 kinase are all within the no-NMD region [47], although the functional relevance of these domains has not yet been fully established.

Van Eeghen et al. [28] reported that individuals with missense mutations in TSC2 had a higher IQ/DQ than those with premature truncation mutations, whereas we observed a tendency for the reverse. This may reflect the smaller sample size in our study. Similarly, van Eeghen et al. observed a lower IQ/DQ for individuals with a mutation in the first half of the protein compared to those with a mutation in the second half, whereas we observed no difference (and a slightly higher IQ/DQ for individuals with 
a mutation in the TSC1-interaction domain). Like van Eeghen et al., we observed little difference between mutations affecting the GAP domain and those that did not.

\section{Length of aberrant tail on TSC2}

In individuals with frameshift mutations, there was a positive but not statistically significant correlation between the length of the aberrant tail and IQ (Figure 1B). This might be explained if longer aberrant tails led to more effective clearing of mutant protein (for which degradation systems have been described [50]) or reduced the deleterious effects of mutant protein.

\section{Model for the effects of mutations}

We propose the following model for the different effects of mutant TSC1 and TSC2 proteins. Mutant TSC1 protein is highly deleterious, although NMD leads to partial reduction of the expression of truncated protein. Mutant protein is degraded slowly, and has an adverse effect on cognitive functions, including IQ/DQ. Proteins with longer aberrant $\mathrm{C}$-terminal tails are more deleterious in this respect. TSC1 protein altered or truncated in the N-terminal 200-300 residues is degraded more rapidly, causing a less severe phenotype. The model is consistent with observations reported by van Eeghen et al. For TSC1, most individuals in their study with truncating mutations up to and including exon 5 showed an IQ/DQ of 70 or more, consistent with our proposal that more rapid clearance of mutant protein in those individuals, leaves them relatively mildly affected [32]. The destabilizing effect of mutations close to the N-terminus of TSC1 is consistent with the existence of a conserved, tightlyfolded domain in this region [46]. 
We suggest that levels of truncated TSC2 protein are also reduced through NMD, with mutations in the no-NMD region leading to more severe, but not lethal, consequences. Mutant protein is degraded more effectively than TSC1, and proteins destabilized by having a long aberrant C-terminal tail are less deleterious.

However, it will be important to test biochemically the predictions of the model for levels and function of mutant TSC1 and TSC2 proteins. If the predictions are correct, it will also be important to understand why longer aberrant $\mathrm{C}$-terminal tails have different effects on TSC1 and TSC2.

Our analysis solely considered genotypes, and other factors will also affect outcomes, illustrated by some individuals with the same mutation having very different IQ/DQ (e.g. TSC2 mutations R751X: IQ/DQ 19, 85, 94; Q1192X: IQ/DQ 19, 79 and R1459X: IQ/DQ 19, 19, 68). These factors include somatic mosaicism [51], modifier genes (perhaps affecting NMD efficiency) [52] and environmental effects such as seizures [28] (although tubers and seizures combined accounted for only $47 \%$ of the variance in IQ in the study of O'Callaghan et al [16]). Nevertheless, it is clear that there are differing effects of distinct mutations in TSC1 and TSC2 (and specific mutations associated with a mild phenotype have been recognized for some time, e.g., [53]). , Larger-scale exploration of the relationship between the molecular consequences of TSC mutations, including direct measurements of levels and function of mutant proteins in vivo, and intellectual phenotype is required to confirm our findings and may lead to discoveries of direct relevance in the clinical setting. 


\section{ACKNOWLEDGEMENTS}

We thank the Tuberous Sclerosis Association, the Wales Gene Park, the National Research Foundation of South Africa, and the Struengmann Fund for financial support. We thank Prof Chris Smith for helpful comments on the manuscript.

Contributors All authors contributed to design, data collection, analysis and interpretation of results. All authors approved the final manuscript submitted.

Competing interests None declared.

Ethics approval Cardiff and Cambridge MRECs.

Provenance and peer review Not commissioned; externally peer reviewed.

Data sharing statement No new data were generated in this study—all data used were contributed to the publically accessible LOVD database (http://chromium. liacs.n1/LOVD2/TSC/home.php). All data referred to in the manuscript are also listed in online supplementary table S1. 


\section{REFERENCES}

1 Curatolo P, Moavero R, de Vries PJ. Neurological and neuropsychiatric aspects of tuberous sclerosis complex. Lancet Neurol 2015;14:733-745.

2 Northrup H, Krueger DA, International Tuberous Sclerosis Complex Consensus Group. Tuberous sclerosis complex diagnostic criteria update: recommendations of the 2012 international tuberous sclerosis complex consensus conference. Pediatr Neurol 2013;49:243-54.

3 van Slegtenhorst M, de Hoogt R, Hermans C et al. Identification of the tuberous sclerosis gene TSC1 on chromosome 9q34. Science 1997; 277:805-808.

4 European Chromosome 16 Tuberous Sclerosis Consortium. Identification and characterization of the tuberous sclerosis gene on chromosome 16. Cell 1993;75:1305-15.

5 Chong-Kopera H, Inoki K, Li Y, Zhu T, Garcia-Gonzalo FR, Rosa JL, Guan KL. TSC1 stabilizes TSC 2 by inhibiting the interaction between TSC 2 and the HERC1 ubiquitin ligase. $J$ Biol Chem 2006;281:8313-8316.

6 Cai SL, Tee AR, Short JD, Bergeron JM, Kim J, Shen J, Guo R, Johnson CL, Kiguchi K, Walker CL. Activity of TSC2 is inhibited by AKT-mediated phosphorylation and membrane partitioning. J Cell Biol 2006;173:279-289.

7 Plank TL, Yeung RS, Henske EP. (1998). Hamartin, the product of the tuberous sclerosis 1 (TSC1) gene, interacts with tuberin and appears to be localized to cytoplasmic vesicles. Cancer Res 1998;58:4766-4770.

8 Hoogeveen-Westerveld M, van Unen L, van den Ouweland A, Hally D, Hoogeveen A, Nellist M. The TSC1-TSC2 complex consists of multiple TSC1 and TSC2 subunits. BMC Biochem 2012;13:18.

9 Dibble CC, Elis W, Menon S, Qin W, Klekota J, Asara JM, Finan PM, Kwiatkowski DJ, Murphy LO, Manning BD TBC1D7 is a third subunit of the TSC1-TSC2 complex upstream of mTORC1. Mol Cell 2012;47:535-546.

10 Tee AR, Manning BD, Roux PP, Cantley LC, Blenis J. Tuberous sclerosis complex gene products, Tuberin and Hamartin, control mTOR signaling by acting as a GTPase-activating protein complex toward Rheb. Curr Biol 2003;13:1259-1268.

11 Inoki K, Li Y, Xu T, Guan KL. Rheb GTPase is a direct target of TSC2 GAP activity and regulates mTOR signaling. Genes Dev 2003;17:1829-1834.

12 World Health Organization. 1993. The ICD-10 Classification of Mental and Behavioural Disorders. Diagnostic Criteria for Research. World Health, Organization, Geneva.

13 Joinson C, O'Callaghan FJ, Osborne JP, Martyn C, Harris T, Bolton PF Learning disability and epilepsy in an epidemiological sample of individuals with tuberous sclerosis complex. Psychol Med 2003;33:335-344.

14 de Vries PJ, Prather PA. The tuberous sclerosis complex. N Engl J Med 2007;356:92.

15 Goodman M, Lamm SH, Engel A, Shepherd CW, Houser OW, Gomez MR. Cortical tuber count: a biomarker indicating neurologic severity of tuberous sclerosis complex. J Child Neurol 1997;12:85-90.

16 O'Callaghan FJ, Harris T, Joinson C, Bolton P, Noakes M, Presdee D, Renowden S, Shiell A, Martyn CN, Osborne JP. The relation of infantile spasms, tubers, and intelligence in tuberous sclerosis complex. Arch Dis Child 2004;89:530-3.

17 de Vries PJ, Howe CJ. The tuberous sclerosis complex proteins - a GRIPP on cognition and neurodevelopment. Trends Mol Med 2007;13:319-326. 
18 Goorden SM, van Woerden GM, van der Weerd L, Cheadle JP, Elgersma Y. Cognitive deficits in Tsc1+/- mice in the absence of cerebral lesions and seizures. Ann Neurol 2007;62:648-655.

19 Ehninger D, Han S, Shilyansky C, Zhou Y, Li W, Kwiatkowski DJ, Ramesh V, Silva AJ. Reversal of learning deficits in a Tsc2+/- mouse model of tuberous sclerosis. Nat Med 2008;14:843-848.

20 Tsai PT, Hull C, Chu Y, Greene-Colozzi E, Sadowski AR, Leech JM, Steinberg J, Crawley JN, Regehr WG, Sahin M. Autistic-like behaviour and cerebellar dysfunction in Purkinje cell Tsc1 mutant mice. Nature 2012;488:647-651.

21 Davies DM, de Vries PJ, Johnson SR, McCartney DL, Cox JA, Serra AL, Watson PC, Howe CJ, Doyle T, Pointon K, Cross JJ, Tattersfield AE, Kingswood JC, Sampson JR. Sirolimus therapy for angiomyolipoma in tuberous sclerosis and sporadic lymphangioleiomyomatosis: a phase 2 trial. Clin Cancer Res 2011;17:4071-4081.

22 Jones AC, Daniells CE, Snell RG, Tachataki M, Idziaszczyk SA, Krawczak M, Sampson JR, Cheadle JP. Molecular genetic and phenotypic analysis reveals differences between TSC1 and TSC2 associated familial and sporadic tuberous sclerosis. Hum Mol Genet 1997;6:2155-2161

23 Dabora SL, Jozwiak S, Franz DN, Roberts PS, Nieto A, Chung J, Choy YS, Reeve MP, Thiele E, Egelhoff JC, Kasprzyk-Obara J, Domanska-Pakiela D, Kwiatkpwski DJ. Mutational analysis in a cohort of 224 tuberous sclerosis patients indicates increased severity of TSC2, compared with TSC1, disease in multiple organs. Am J Hum Genet 2001;68:64-80.

24 Lewis JC, Thomas HV, Murphy KC. Genotype and psychological phenotype in tuberous sclerosis. J Med Genet 2004;41:203-207.

25 Sancak O, Nellist M, Goedbloed M, Elfferich P, Wouters C, Maat-Kievit A, Zonnenberg B, Verhoef S, Halley D, van den Ouweland A. Mutational analysis of the TSC1 and TSC2 genes in a diagnostic setting: genotype - phenotype correlations and comparison of diagnostic DNA techniques in Tuberous Sclerosis Complex. Eur J Hum Genet 2005;13:731-741.

26 Au KS, Williams AT, Roach ES, Batchelor L, Sparagana SP, Delgado MR, Wheless JW, Baumgartner JE, Roa BB, Wilson CM, Smith-Knuppel TK, Cheung MY, Whittemore VH, King TM, Northrup H. Genotype/phenotype correlation in 325 individuals referred for a diagnosis of tuberous sclerosis complex in the United States. Genet Med 2007;9:88-100.

27 Jansen FE, Braams O, Vincken KL, Algra A, Anbeek P, Jennekens-Schinkel A, Halley D, Zonnenberg BA, van den Ouweland A, van Huffelen AC, van Nieuwenhuizen O, Nellist M. Overlapping neurologic and cognitive phenotypes in patients with TSC1 or TSC2 mutations. Neurology 2008;70:908-915.

28 van Eeghen AM, Black ME, Pulsifer MB, Kwiatkowski DJ, Thiele EA. Genotype and cognitive phenotype of patients with tuberous sclerosis complex. Eur J Hum Genet 2012:20:510-515.

29 Nagy E, Maquat LE. A rule for termination-codon position within introncontaining genes: when nonsense affects RNA abundance. Trends Biochem Sci 1998;23:198-199.

30 Jeganathan D, Fox MF, Young JM, Yates JRW, Osborne JP, Povey S. Nonsensemediated RNA decay in the TSC1 gene suggests a useful tool pre- and postpositional cloning. Hum Genet 2002;111:555-565.

31 Mozaffari M, Hoogeveen-Westerveld M, Kwiatkowski D, Sampson J, Ekong R, Povey S, den Dunnen JT, van den Ouweland A, Halley D, Nellist M. 
Identification of a region required for TSC1 stability by functional analysis of TSC1 missense mutations found in individuals with tuberous sclerosis complex. BMC Med Genet 2009;10:88.

32 Hoogeveen-Westerveld M, Exalto C, Maat-Kievit A, van den Ouweland A, Halley D, Nellist M. Analysis of TSC1 truncations defines regions involved in TSC1 stability, aggregation and interaction. Biochim Biophys Acta 2010;1802;774-781.

33 Hoogeveen-Westerveld M, Wentink M, van den Heuvel D, Mozaffari M, Ekong R, Povey S, den Dunnen JT, Metcalfe K, Vallee S, Krueger S, Bergoffen J, Shashi V, Elmslie F, Kwiatkowski D, Sampson J, Vidales C, Dzarir J, GarciaPlanells J, Dies K, Maat-Kievit A, van den Ouweland A, Halley D, Nellist M. Functional assessment of variants in the TSC1 and TSC2 genes identified in individuals with Tuberous Sclerosis Complex. Hum Mutat 2011;32:424-435.

34 Tierney KM, McCartney DL, Serfontein JR, de Vries PJ. Neuropsychological attention skills and related behaviours in adults with tuberous sclerosis complex. Behav Genet 2011;41:437-444.

35 Roach ES, Gomez MR, Northrup H. Tuberous sclerosis complex consensus conference: revised clinical diagnostic criteria. J Child Neurol 1998;13:624-628.

36 Wechsler D. 1981. Wechsler Adult Intelligence Scale - Revised. Psychological Corporation, London.

37 Wechsler D. 1992. Wechsler Intelligence Scale for Children - III. Psychological Corporation, London.

38 Raven J, Raven JC, Court JH. 1998. Coloured Progressive Matrices. Oxford Psychologists Press, Oxford.

39 Sparrow SS, Balla DA, Cicchetti DV. 1984. Vineland Adaptive Behavior Scales. Circle Press, Minnesota.

40 Wechsler D. 1999. Wechsler Abbreviated Scale of Intelligence. Psychological Corporation, London.

41 World Health Organization. 1994. The ICD-10 Classification of Mental and Behavioural Disorders. Clinical Descriptions and Diagnostic Guidelines. World Health Organization, Geneva.

42 Jones AC, Shyamsundar MM, Thomas MW, Maynard J, Idziaszczyk S, Tomkins S, Sampson JR, Cheadle JP. Comprehensive mutation analysis of TSC1 and TSC2-and phenotypic correlations in 150 families with tuberous sclerosis. $\mathrm{Am} \mathrm{J}$ Hum Genet 1999;64:1305-1315.

43 Jones AC, Sampson JR, Hoogendoorn B, Cohen D, Cheadle JP. Application and evaluation of denaturing HPLC for molecular genetic analysis in tuberous sclerosis. Hum Genet 2000;106:663-668.

44 Larkin MA, Blackshields G, Brown NP, Chenna R, McGettigan PA, McWilliam H, Valentin F, Wallace IM, Wilm A, Lopez R, Thompson JD, Gibson TJ, Higgins DG. Clustal W and Clustal X version 2.0. Bioinformatics 2007; 23:2947-2948.

45 http://chromium.liacs.nl/LOVD2/TSC/home.php

46 Sun W, Zhu YJ, Wang Z, Zhong Q, Gao F, Lou J, Gong W, Xu W. Crystal structure of the yeast TSC1 core domain and implications for tuberous sclerosis pathological mutations. Nature Comms 2013;4:2135

47 Serfontein J, Nisbet RER, Howe CJ, de Vries PJ. Conservation of structural and functional elements of TSC1 and TSC2: a bioinformatic comparison across animal models. Behav Genet 2011;41:349-356. 
48 Kwiatkowski DJ. Genetics of Tuberous Sclerosis Complex. In Kwiatkowski DJ, Whittemore VH, Thiele EA eds. Tuberous Sclerosis Complex: Genes, Clinical Features and Therapeutics pp29-60. Wiley, Wienheim 2010.

49 Lamb RF, Roy C, Diefenbach TJ, Vinters HV, Johnson MW, Jay DG, Hall A. The TSC1 tumour suppressor hamartin regulates cell adhesion through ERM proteins and the GTPase Rho. Nat Cell Biol 2000;2:281-287.

50 Han S, Witt RM, Santos TM, Polizzano C, Sabatini BL, Ramesh V. Pam (Protein associated with Myc) functions as an $\mathrm{E} 3$ ubiquitin ligase and regulates TSC/mTOR signaling. Cell Signal 2008;20:1084-1091.

51 Emmerson P, Maynard J, Jones S, Butler R, Sampson JR, Cheadle JP. Characterizing mutations in samples with low-level mosaicism by collection and analysis of DHPLC fractionated heteroduplexes. Hum Mutat 2003;21:112-115.

52 Seoighe C, Gehring C. Heritability in the efficiency of nonsense-mediated mRNA decay in humans. PLoS One 2010;5:e11657

53 Jansen AC, Sancak O, D'Agostino MD, Badhwar A, Roberts P, Gobbi G, Wilkinson R, Melanson D, Tampieri D, Koenekoop R, Gans M, Maat-Kievit A, Goedbloed M, van den Ouweland AMW, Nellist M, Pandolfo M, McQueen M, Sims K, Thiele EA, Dubeau FA, Andermann F, Kwiatkowski DJ, Halley DJJ, Andermann E. Unusually mild tuberous sclerosis phenotype is associated with TSC2 R905Q mutation. Ann Neurol 2006; 60:528-539. 


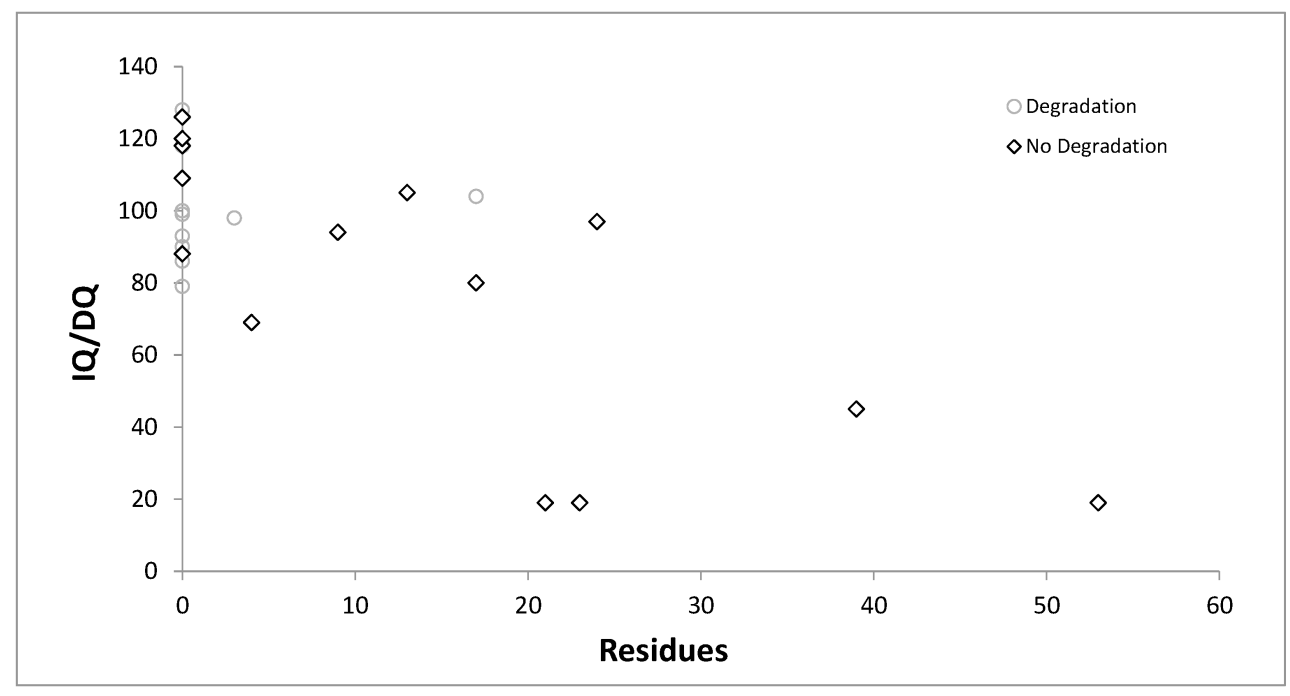

1A

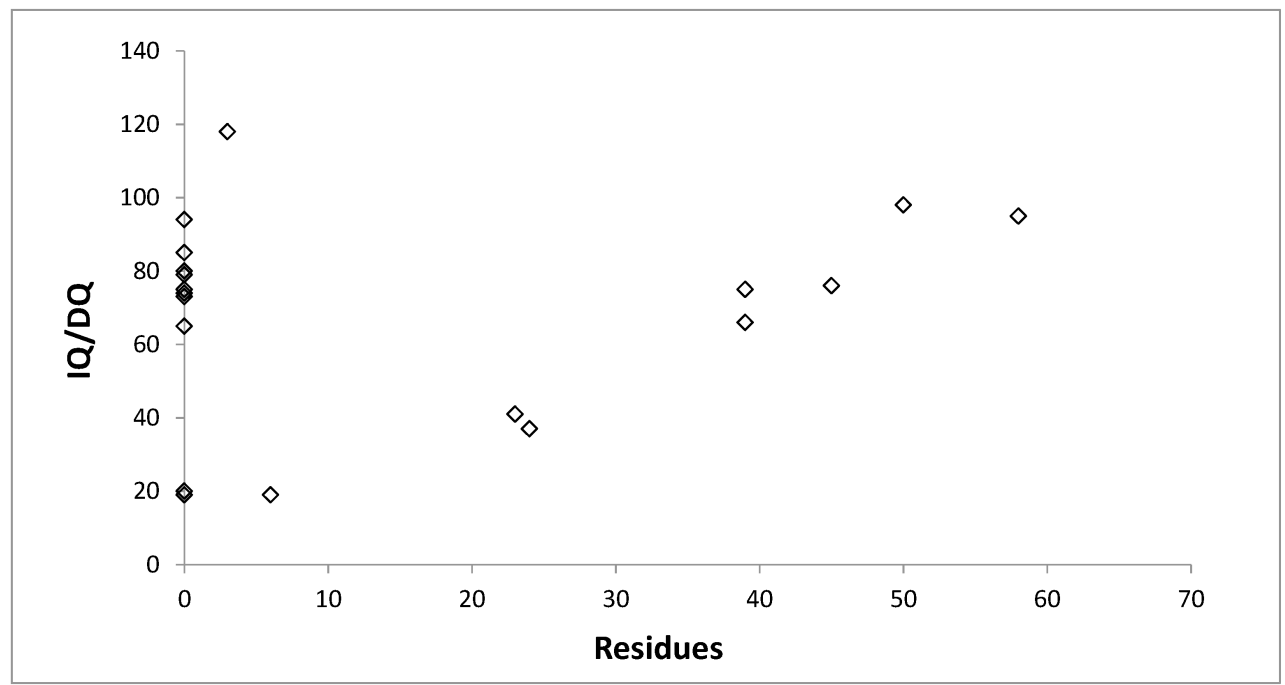

IB

Page 29 of 30 


\section{Figure Legend}

Figure 1 Correlations between IQ/DQ and the length of predicted aberrant C-terminal tail of nonsense and frameshift mutations. A) TSC1 mutations with and without predicted protein degradation, B) TSC2 mutations not predicted to be subject to NMD. For both panels the $y$-axis indicates IQ/DQ and the $\mathrm{x}$-axis length of the predicted aberrant $\mathrm{C}$-terminal tail arising from frameshift mutations ( 0 for nonsense mutations). For TSC1 cases where mutant protein was not expected to be degraded, there was a strong negative correlation between the length of the C-terminal aberrant tail and IQ/DQ (rho $=-0.706 ; \mathrm{p}=0.003$ ). 
Supplementary Table 1. List of individual patient mutations, familial or sporadic status of mutation and best estimate IQ/DQ by TSC1 and TSC2.

\begin{tabular}{|c|c|c|c|c|c|}
\hline Mutation & Familial/Sporadic & IQ & Mutation & Familial/Sporadic & IQ \\
\hline TSC1 & & & TSC2 continued & & \\
\hline R37SP & Familial & 108 & S946SP & Sporadic & 65 \\
\hline S91X & Unknown & 86 & T993SP & Sporadic & 99 \\
\hline S91X & Familial & 79 & R1032X & Sporadic & 19 \\
\hline W103X & Sporadic & 118 & G1133FSX & Sporadic & 95 \\
\hline S108FSX & Unknown & 104 & Q1192X & Sporadic & 19 \\
\hline R245X & Sporadic & 128 & Q1192X & Sporadic & 79 \\
\hline Q328X & Familial & 93 & Q1419X & Sporadic & 73 \\
\hline Q328X & Familial & 90 & S1433X & Sporadic & 65 \\
\hline Q328FSX & Familial & 98 & R1459X & Sporadic & 73 \\
\hline S334X & Sporadic & 99 & R1459X & Sporadic & 19 \\
\hline T339X & Sporadic & 100 & R1459X & Sporadic & 19 \\
\hline H371FSX & Sporadic & 69 & P1497R & Sporadic & 19 \\
\hline T417FSX & Familial & 97 & F1499FSX & Sporadic & 37 \\
\hline Q527FSX & Familial & 80 & V1531FSX & Sporadic & 76 \\
\hline N634FSX & Sporadic & 19 & L1594M & Sporadic & 19 \\
\hline Q701FSX & Sporadic & 19 & N1643K & Sporadic & 117 \\
\hline R715FSX & Sporadic & 94 & Q1665X & Sporadic & 20 \\
\hline W750X & Sporadic & 109 & P1675K & Unknown & 38 \\
\hline R786X & Sporadic & 88 & N1681K & Sporadic & 19 \\
\hline R786X & Sporadic & 88 & M1691SP & Sporadic & 72 \\
\hline E788X & Familial & 126 & M1721SP & Sporadic & 54 \\
\hline R804FSX & Sporadic & 19 & P1737FS & Sporadic & 55 \\
\hline E890FSX & Sporadic & 105 & R1743P & Sporadic & 19 \\
\hline R892FSX & Sporadic & 45 & H1746del & Sporadic & 65 \\
\hline Q898X & Familial & 118 & H1746del & Sporadic & 50 \\
\hline \multirow[t]{2}{*}{ Q898X } & Familial & 120 & H1746del & Sporadic & 84 \\
\hline & & & T1780FS & Sporadic & 19 \\
\hline \multirow[t]{2}{*}{$T S C 2$} & & & F1803FS & Sporadic & 19 \\
\hline & & & Large Deletion & Sporadic & 24 \\
\hline L259SP & Sporadic & 34 & Large Deletion & Familial & 81 \\
\hline G294E & Familial & 21 & Large Deletion & Sporadic & 19 \\
\hline Y336X & Sporadic & 74 & Large Deletion & Sporadic & 19 \\
\hline I365DEL & Sporadic & 85 & Large Deletion & Sporadic & 19 \\
\hline P419SP & Sporadic & 87 & Large Deletion & Sporadic & 19 \\
\hline R458X & Sporadic & 19 & Large Deletion & Sporadic & 19 \\
\hline E482SP & Sporadic & 75 & Large Deletion & Sporadic & 25 \\
\hline I496FSX & Familial & 66 & Large Deletion & Sporadic & 105 \\
\hline R505X & Sporadic & 80 & Large Deletion & Familial & 41 \\
\hline Y598X & Sporadic & 75 & Large Deletion & Sporadic & 82 \\
\hline R611Q & Sporadic & 80 & Large Deletion & Sporadic & 19 \\
\hline R611Q & Sporadic & 33 & Large Deletion & Sporadic & 19 \\
\hline $\mathrm{R} 611 \mathrm{~W}$ & Familial & 50 & Large Deletion & Sporadic & 105 \\
\hline $\mathrm{R} 611 \mathrm{~W}$ & Sporadic & 19 & Large Deletion & Sporadic & 100 \\
\hline R611W & Sporadic & 19 & Large Deletion & Sporadic & 114 \\
\hline A614D & Sporadic & 38 & Large Deletion & Sporadic & 100 \\
\hline T659FSX & Sporadic & 75 & Large Deletion & Sporadic & 94 \\
\hline A675FSX & Sporadic & 41 & & & \\
\hline V692FSX & Sporadic & 19 & & & \\
\hline R751X & Sporadic & 85 & & & \\
\hline R751X & Sporadic & 94 & & & \\
\hline $\mathrm{R} 751 \mathrm{X}$ & Sporadic & 19 & & & \\
\hline A765FSX & Sporadic & 19 & & & \\
\hline Q785SP & Sporadic & 19 & & & \\
\hline Q785SP & Sporadic & 112 & & & \\
\hline Y790X & Sporadic & 19 & & & \\
\hline L844FSX & Sporadic & 98 & & & \\
\hline S879FSX & Sporadic & 118 & & Pag & 1 of 5 \\
\hline
\end{tabular}


Supplementary Table 2. Means $(\mu)$ and standard deviations $(\sigma)$ of IQ/DQ with different gender in different TSC status.

\begin{tabular}{lccccc}
\hline Gender status & Number & $\boldsymbol{\mu}$ & $\boldsymbol{\sigma}$ & $\mathbf{Z}$ value & $\mathbf{P}$ \\
\hline All subjects & 47 & 62.0 & 36.5 & & \\
Males & 53 & 63.5 & 35.9 & & \\
Females & & & & -0.164 & 0.870 \\
Males vs Females & & & & & \\
TSC1 & 10 & 89.3 & 33.9 & & \\
Males & 16 & 87.9 & 30.6 & & \\
Females & & & & 0.343 & 0.732 \\
Males vs Females & & & & & \\
TSC2 & 37 & 54.6 & 33.9 & & \\
Males & 37 & 53.0 & 33.2 & & \\
Females & & & & 0.182 & 0.856 \\
Males vs Females & & & & & \\
\hline
\end{tabular}

Statistical comparisons were made with the Mann-Whitney U test. * denotes a statistically significant result.

Supplementary Table 3. Spearman's rank correlations for TSC1 and TSC2 aberrant tail length and IQ/DQ. Only individuals with nonsense and frameshift mutations are included. Individuals with missense (TSC2) or splice site (TSC1 and TSC2) mutations are excluded.

\begin{tabular}{lccc} 
& N & $\boldsymbol{\rho}$ & $\boldsymbol{P}$ \\
\hline TSC1 all subjects & 25 & -0.539 & $0.005^{*}$ \\
TSC1 no degradation & 15 & -0.706 & $0.003^{*}$ \\
TSC1 degradation & 10 & 0.199 & 0.582 \\
TSC1 frameshift & 11 & -0.552 & 0.078 \\
& & & \\
TSC2 all subjects & 30 & 0.092 & 0.628 \\
TSC2 no NMD & 3 & 0.866 & 0.333 \\
TSC2 NMD & 27 & 0.308 & 0.119 \\
TSC2 frameshift & 13 & -0.031 & 0.921 \\
TSC2 frameshift NMD & 10 & 0.422 & 0.224 \\
\hline
\end{tabular}


$\mathrm{TSCl}$

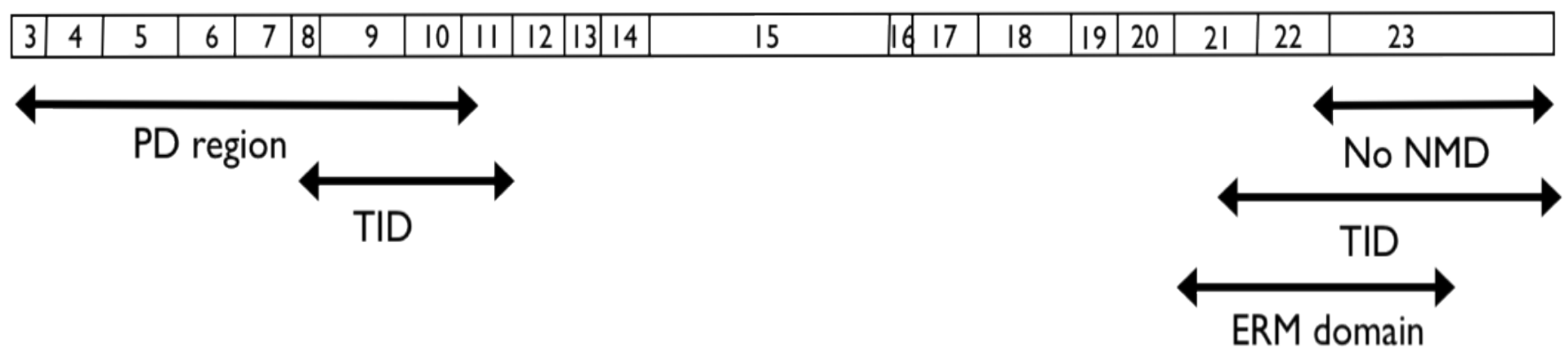

TSC2

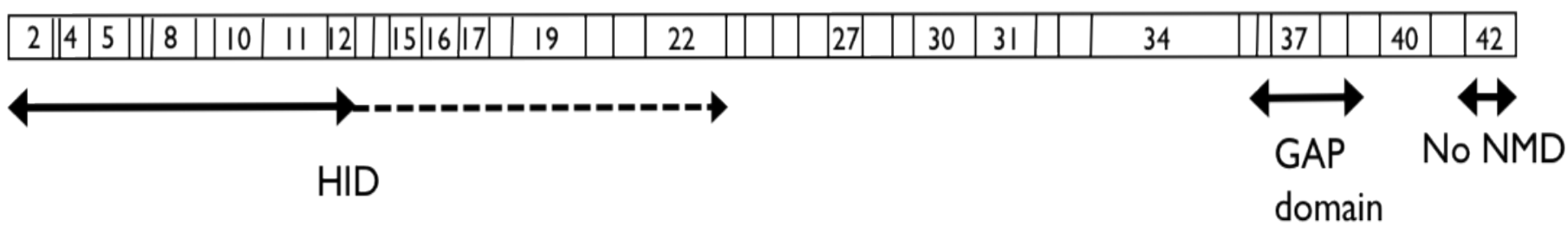

Supplementary Figure 1. Schematic representation of the regions of the TSC1 and TSC2 proteins considered here. Exon sizes are represented approximately to scale. Exon numbers correspond to those in the reference sequences used in the analysis. Numbers of some exons for TSC2 have been omitted for clarity. $\mathrm{NMD}=$ nonsense mediated decay; $\mathrm{PD}=$ protein degradation; TID = tuberin interaction domain; HID = hamartin interaction domain (see text for discussion of extent of this); GAP = GTPase activating protein; ERM = (Ezrin-Radixin-Moesin)-binding 
A (all subjects)

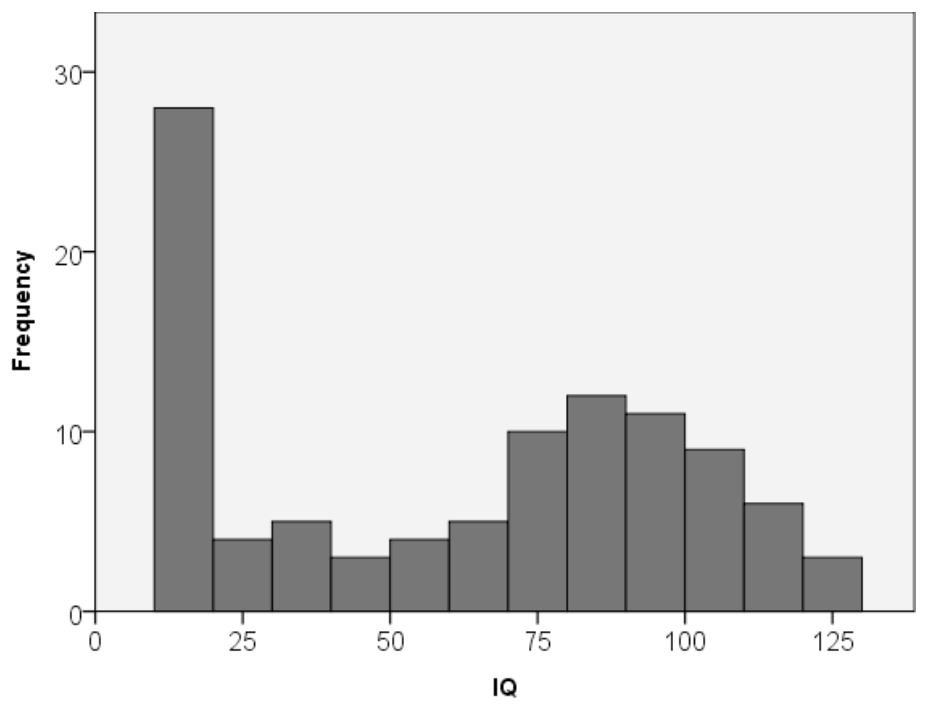

B (TSC1)

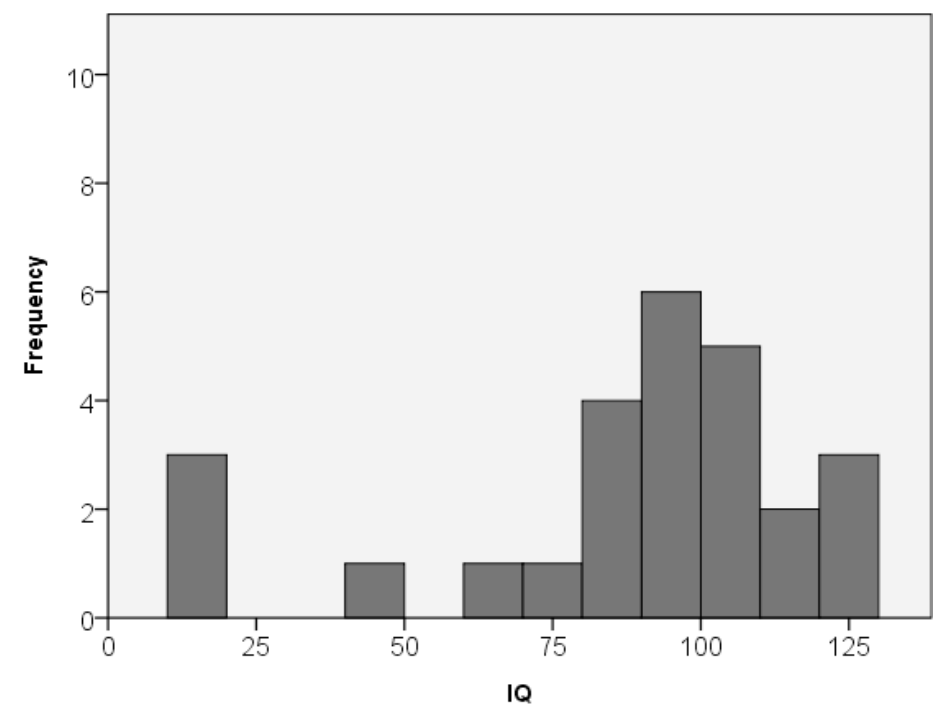

C (TSC2)

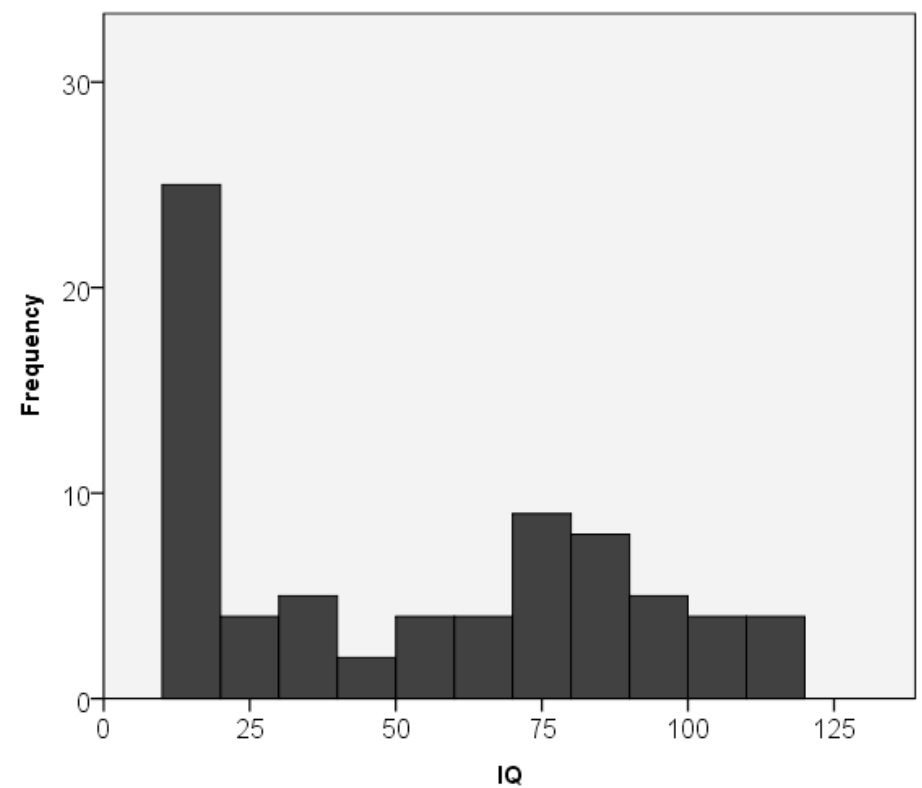

Supplementary Figure 2. Histograms showing the bimodal distribution of IQ/DQ in the study. A) The total sample $(\mathrm{n}=100), \mathrm{B}) T S C 1$ group $(\mathrm{n}=26), \mathrm{C}) T S C 2$ group $(\mathrm{n}=74)$. 
A

(TSC1)

B

(TSC2)

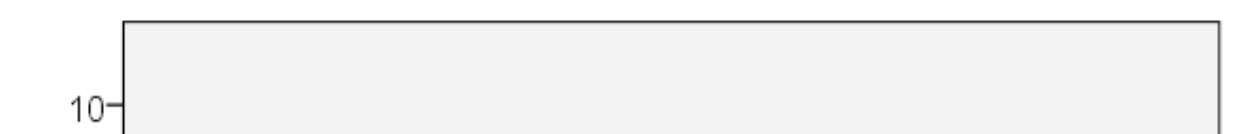

Type of mutation

$\square$ Missense conservative

$\square$ Missense non-conservative

$\square$ Nonsense

$\square$ Frameshift

$\square$ Large deletions

$\square$ Inframe deletions

$\square$ Splice site
Type of mutation

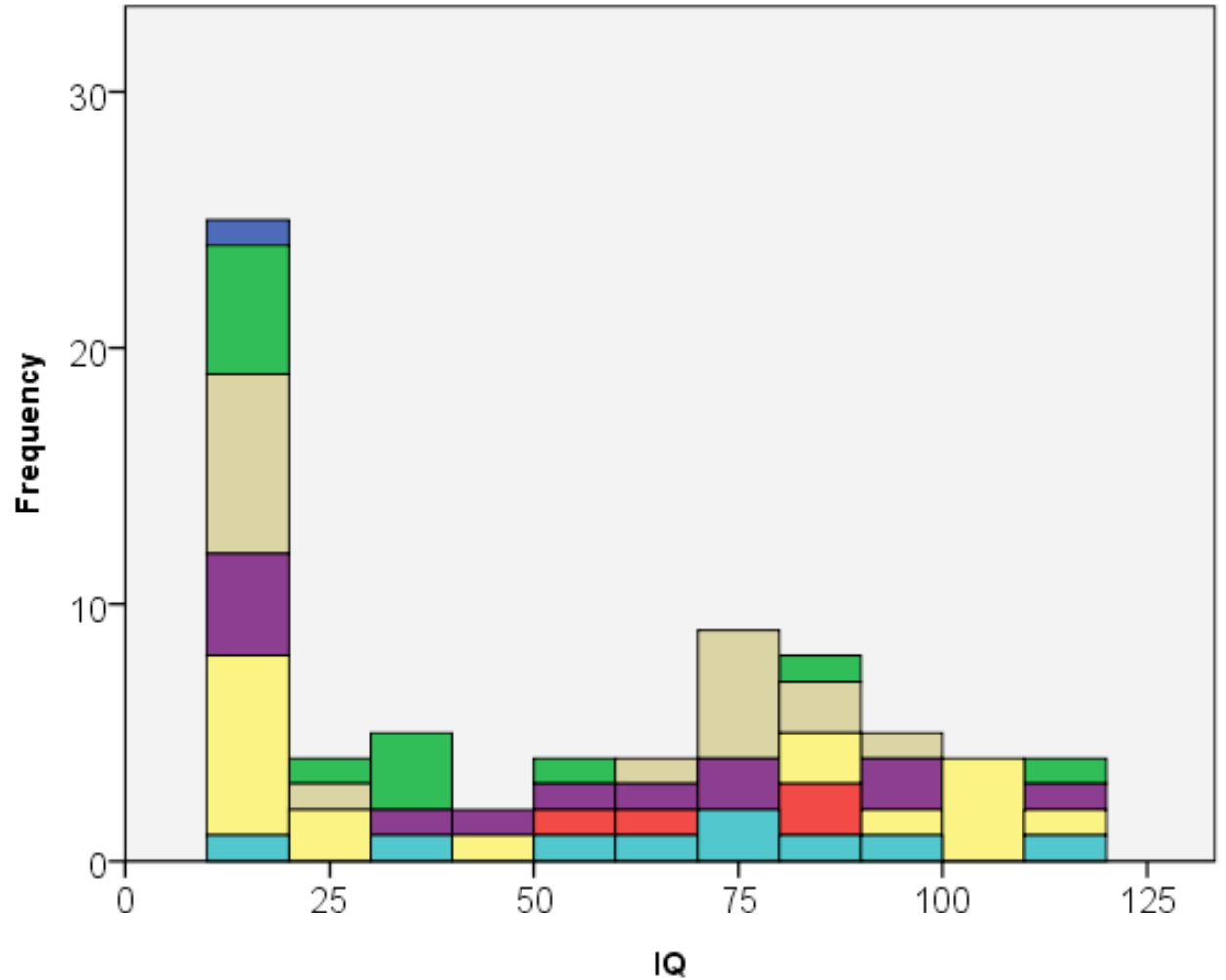

$\square$ Missense conservative

$\square$ Missense non-conservative

$\square$ Nonsense

$\square$ Frameshift

$\square$ Large deletions

$\square$ Inframe deletions

$\square$ Splice site

Supplementary Figure 3. Stacked histogram of IQ/DQ in relation to type of mutation. A) TSCI mutations, B) TSC2 mutations. 